\title{
Demographic parameters of black-browed albatrosses Thalassarche melanophris from the Falkland Islands
}

\author{
Paulo Catry $\cdot$ Jaume Forcada $\cdot$ Ana Almeida
}

Received: 28 April 2010/Revised: 18 February 2011/Accepted: 21 February 2011/Published online: 8 March 2011

(C) Springer-Verlag 2011

\begin{abstract}
Black-browed albatrosses Thalassarche melanophris are currently classified as globally endangered. The most important populations of this species are believed to be declining due to, amongst other factors, unsustainable levels of incidental mortality in fishing gear. However, detailed demographic data are lacking for several critical populations, including the largest of all, nesting in the Falkland Islands. Here, we present data from the first Falkland Islands detailed demographic study (at New Island) and show that, from 2003 to 2009, the mean adult survival probability was 0.942 (95\% CI: $0.930-0.952$ ). Nesting frequency of adults is amongst the highest recorded for Thalassarche albatrosses and breeding success ( 0.564 chicks per egg) is within normal values. The nesting population in the intensively studied plots experienced an increase of 4\% per year from 2004 to 2009 . These results indicate that the Falklands population may not be as threatened as previously supposed, although studies from more sites and a longer time series are needed to confirm or refute this. The high survival rates may partly reflect recent efforts to mitigate bycatch made by the Falkland Islands and other fisheries in the region. The reinforcement of such initiatives may be critical to buffer the black-browed
\end{abstract}

P. Catry $(\bowtie) \cdot$ A. Almeida

Eco-Ethology Research Unit, ISPA, Rua Jardim do Tabaco 34, 1149-041 Lisbon, Portugal

e-mail: paulo.catry@gmail.com

P. Catry · A. Almeida

Museu Nacional de História Natural, Rua da Escola Politécnica, Lisbon, Portugal

J. Forcada

British Antarctic Survey, Natural Environment

Research Council, High Cross, Madingley Road,

Cambridge CB3 OET, UK albatross population against ecosystem shifts and natural disasters (such as harmful algal blooms) that will likely become more frequent with ongoing global changes.

Keywords New Island · Bycatch · Demography · Red tide Patagonian shelf

\section{Introduction}

Black-browed albatrosses Thalassarche melanophris are currently classified as globally endangered (IUCN 2008), and the main factor believed to be threatening their populations is accidental bycatch in several types of fisheries (Arnold et al. 2006; Poncet et al. 2006; Huin and Reid 2007). An estimated $67 \%$ of the global population of this albatross species nests on the Falkland Islands (ACAP 2009), and, hence, its global conservation is considerably dependent on the fate of this particular population. Systematic surveys of the Falkland nesting grounds have resulted in reports of a sustained decline of $0.7-1.0 \%$ per annum (Huin and Reid 2007), while other monitoring efforts concluded that the population was increasing (Strange 2008). The enormous size of the main Falkland Islands colonies presents serious challenges to the rigorous assessment of nesting numbers and trends.

In recent years, important efforts have been made to reduce accidental mortality of seabirds in the marine range of Falkland black-browed albatrosses (e.g., Sullivan et al. 2006a; González-Zevallos et al. 2007; Moreno et al. 2008), which may have had some positive effects on their population dynamics. However, and contrasting to the attention directed at determining population size and trends (Huin and Reid 2007; Strange 2008 and references therein), there are no published estimates of other demographic 
parameters. The determination of such parameters may help to improve the current and future understanding of the threatening factors (and the efforts needed for their mitigation) affecting black-browed albatrosses in the region.

Here, we present the initial results of the first demographic study of a nesting black-browed albatross colony of the Falkland Islands.

\section{Methods}

Fieldwork

Our detailed demographic study takes place at the Settlement rookery on New Island $\left(51^{\circ} 42^{\prime} \mathrm{S}, 61^{\circ} 18^{\prime} \mathrm{W}\right)$, West Falkland. New Island hosts a total of ca 10-13,000 blackbrowed albatross nesting pairs (Huin and Reid 2007; Strange 2008). Here, egg laying takes place in October, hatching in December, and fledging in April. Study birds were initially marked (ringed with unique monel and darvic rings) in November 2003 (incubation period). All nesting individuals in 5 discrete sub-colonies and in a specific sector of a larger 6th sub-colony were marked. In subsequent years (up until the 2009-2010 nesting season), all nests in the study plots were visited daily during egg laying, the identities of the birds seen were recorded, and their status (breeding or non-breeding) assessed. All nests were permanently tagged for easy identification and monitoring of the breeding attempt. All new recruits to the study plots found in association with an egg were immediately ringed. Adult birds were sexed using one of the several techniques: observation of copulation, preincubation attendance patterns (only males spend continuous periods of several days guarding the nest before laying takes place), molecular sexing from a blood sample or association with a bird of known sex. Nests were regularly visited until the end of February/early March each year to assess egg and chick survival (chick mortality after the end of February is negligible-own unpubl. data).

From 2004-2005 until 2010-2011, in addition to recording the number of active nests (nests with egg) in the intensively studied sub-colonies, the number of nests with an egg in a further sub-colony of the Settlement Rookery was counted each year, 1-2 days after the completion of egg laying. The sum of the above mentioned totals gives an indication of population trends at the local level.

Estimates of demographic parameters

We combined the encounter histories of breeding individuals for the seasons 2003-2009 to estimate their survival
Table 1 Numbers of black-browed albatrosses at each of six study sub-colonies of New Island, Falkland Islands, by sex

\begin{tabular}{lcrrrrrr}
\hline & \multicolumn{2}{l}{ Sub-colony } & & & & & \\
\cline { 2 - 8 } & A & B & C & D & E & F & Total \\
\hline Males & 70 & 63 & 144 & 23 & 30 & 5 & 335 \\
Females & 73 & 60 & 147 & 18 & 29 & 3 & 330 \\
Unknown & 13 & 6 & 28 & 1 & 5 & 0 & 53 \\
All & 156 & 129 & 319 & 42 & 64 & 8 & 718 \\
\hline
\end{tabular}

and breeding probabilities. This involved 718 individual birds over 7 time intervals of 1 year. The distribution of individuals by sub-colony and sex is shown in Table 1. For these birds, we estimated the probabilities of survival and transition between different reproductive stages using a multistate capture-mark-recapture (CMR) analysis (Lebreton and Pradel 2002). We used a simplified life cycle for black-browed albatrosses with three breeding stages as defined in Fig. 1, following Nevoux et al. (2010). In a given year, a breeding bird was successful (S) or failed (F) if it fledged or failed to fledge its chick, respectively. Non-breeders $(\mathrm{N})$ were birds that did not attempt to breed but were observed in the colonies. Individual encounter histories could be grouped according to sex and subcolony, but we only retained sex as a grouping variable because most of the six sub-colonies studied had relatively low numbers of birds. To model the encounter histories for this life cycle, we considered the general Arnason-Schwarz (AS) multistate CMR model, $p(t * s), \phi(t * s), \psi^{i, j}(t * s)$, where probabilities of recapture $(p)$, survival $(\phi)$, and transition from reproductive stages $i$ to $j\left(\psi^{i, j}\right)$ varied according to sex (s) and encounter occasion ( $t$ ), and the interaction between these variables. The goodness-of-fit

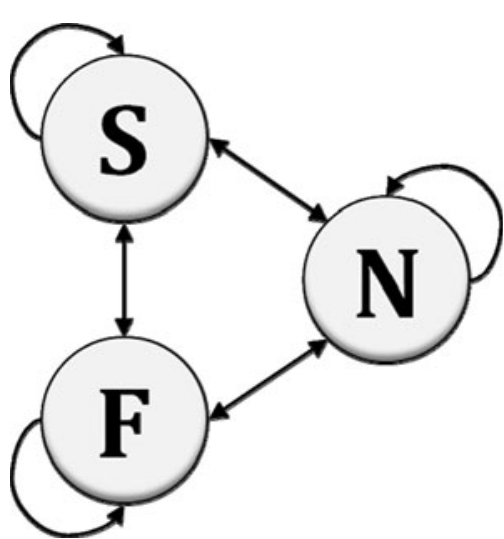

Fig. 1 Life cycle of the black-browed albatross used to build markrecapture models including three reproductive stages: $S$ are successful breeders, $F$ are failed breeders, and $N$ are non-breeders. Arrows represent possible interannual transitions between stages 
Table 2 Goodness-of-fit tests for multistate CMR models of the black-browed albatross dataset of New Island. Tests are based on Pradel et al. (2003) and Choquet et al. (2009)

\begin{tabular}{|c|c|c|c|c|c|c|c|c|}
\hline & & \multicolumn{7}{|c|}{ Goodness-of-fit test components } \\
\hline & & WBWA & 3G.SR & 3G.SM & $3 \mathrm{G}$ & M.ITEC & M & $3 G+M$ \\
\hline \multirow[t]{3}{*}{ Males } & $\chi^{2}$ & 30.74 & 9.33 & 24.74 & 64.80 & 34.97 & 34.97 & 99.77 \\
\hline & $d f$ & 26 & 10 & 32 & 68 & 3 & 3 & 71 \\
\hline & $\hat{c}$ & 1.18 & 0.93 & 0.77 & 0.95 & 11.66 & 11.66 & 1.40 \\
\hline \multirow[t]{3}{*}{ Females } & $\chi^{2}$ & 21.10 & 4.50 & 20.37 & 45.96 & 17.91 & 17.91 & 63.86 \\
\hline & $d f$ & 23 & 10 & 31 & 64 & 3 & 3 & 67 \\
\hline & $\hat{c}$ & 0.92 & 0.45 & 0.66 & 0.72 & 5.97 & 5.97 & 0.95 \\
\hline \multirow[t]{3}{*}{ Sexes pooled } & $\chi^{2}$ & 50.22 & 6.19 & 35.76 & 92.17 & 48.00 & 48.00 & 140.17 \\
\hline & $d f$ & 31 & 10 & 41 & 82 & 3 & 3 & 85 \\
\hline & $\hat{c}$ & 1.62 & 0.62 & 0.87 & 1.12 & 15.99 & 15.99 & 1.65 \\
\hline
\end{tabular}

Component 3G is the sum of tests WBWA, 3G.SR and 3G.SM and component M sums M.ITEC and M.LTEC. The sum of 3G and M provides an overall test for each data group. Adjustment factor $\hat{c}$ is $\chi^{2} / d f$, where $\chi^{2}$ is the chi-square statistic and $d f$ are degrees of freedom. $\hat{c}$ values above 1 indicate extrabinomial variation and lack of fit

(GOF) of this model was tested using the methods of Pradel et al. (2003) as implemented in the U-Care software (Choquet et al. 2009). After the GOF results, we used the M-SURGE software (Choquet et al. 2004) and a selection procedure based on the Akaike's information criterion (AIC; Burnham and Anderson 1998), aiming at the sequential simplification of the AS model and to obtain a more parsimonious but appropriate model. For parameter inference, we selected a logit link function to estimate recapture and survival probabilities, and a generalized logit link function for transition probabilities to constrain estimates within the interval $[0,1]$. Standard errors were derived from the variance-covariance matrix of the maximum likelihood estimates.

We analyzed breeding success $(\sigma)$, defined as the probability to fledge a chick for those birds that attempted breeding (laid an egg). We fitted generalized linear models with a binomial error distribution, using the statistical software R (R Development Core Team 2009), to the data on observed breeding outcomes at each encounter occasion. The main explanatory variable for $\sigma$ was the encounter occasion. We selected a logit link function to constrain $\sigma$ within $[0,1]$. We compared a model with timevariant breeding success with a time-invariant model, selecting the best one according to the lowest AIC corrected for overdispersion, with an overdispersion parameter estimated during model fit.

We estimated the growth rate of the population $(\lambda)$ over the study period (excluding the first year, because not all birds in the study colonies were ringed) using the encounter histories of the ringed birds in a new CMR study, with Jolly-Seber models for recruitment and population growth rate using Pradel's (1996) parameterisation and software MARK (White and Burnham 1999).

\section{Results}

Goodness-of-fit test for CMR models

The analysis was based on the encounter histories of 665 sexed birds, excluding 53 unsexed birds of which all but 6 were ringed at the last encounter occasion. Over the study period, the most commonly observed breeding states were failed breeder for both sexes (51 and 53\% of observations for males and females) and successful breeder (39 and $41 \%$ for males and females). GOF tests were carried out for each sex and the two sexes pooled; the main results are in Table 2 . The tests by sex did not indicate effects of transience (test $3 \mathrm{G}$; many birds being detected at their first capture occasion only), but indicated strong effects of trap dependence for both sexes (test $\mathrm{M}$; pooled sexes $\chi^{2}=47.50, d f=3$, $P<0.001)$. Non-random transitions between stages were found for both sexes pooled (test WBWA; $\chi^{2}=50.22$, $d f=31, P<0.016$ ), but were non-significant for each sex, suggesting different heterogeneity in stage transitions between males and females, and the support of the AS model with sex effects. The test statistic values combined produced a variance inflation factor $(\hat{c})$ of 1.65 (Table 2). Thus, starting from the sex-specific AS model, we used this estimate of $\hat{c}$ to correct the AIC for overdispersion (QAIC, Brunham and Anderson 1998) to select more parsimonious CMR model structures and for inference.

CMR and breeding success analysis model selection

Table 3 shows the summary of the CMR model selection, only including fitted models that substantially reduced the $\triangle \mathrm{QAIC}$ in comparison with previously fitted models; model structures with QAIC differences lower than 2 with respect to models on 
Table 3 Model selection for recapture $(p)$, survival $(\phi)$, and transition $\left(\psi^{i, j}\right)$ probabilities of black-browed albatrosses at New Island

\begin{tabular}{|c|c|c|c|c|c|c|c|c|c|c|c|c|c|}
\hline & \multicolumn{3}{|c|}{ Recapture } & \multicolumn{3}{|c|}{ Survival } & \multicolumn{3}{|c|}{ Transitions } & \multirow[t]{2}{*}{$N p$} & \multirow[t]{2}{*}{ Deviance } & \multirow[t]{2}{*}{ QAIC } & \multirow[t]{2}{*}{$\Delta \mathrm{QAIC}$} \\
\hline & $p^{S}$ & $p^{F}$ & $p^{N}$ & $\phi^{S}$ & $\phi^{F}$ & $\phi^{N}$ & $\psi^{S,-}$ & $\psi^{F,-}$ & $\psi^{N,-}$ & & & & \\
\hline 1 & $\mathrm{t}^{*} \mathrm{~s}$ & $\mathrm{t} * \mathrm{~s}$ & $\mathrm{t}^{*} \mathrm{~s}$ & $\mathrm{t}^{*} \mathrm{~s}$ & $\mathrm{t} * \mathrm{~s}$ & $\mathrm{t}^{*} \mathrm{~s}$ & $\mathrm{t}^{*} \mathrm{~s}$ & $\mathrm{t} * \mathrm{~s}$ & $\mathrm{t}^{*} \mathrm{~s}$ & 128 & 5862.2 & 3808.9 & 138.7 \\
\hline 2 & $\mathrm{~s}$ & $\mathrm{~s}$ & $\mathrm{~s}$ & $\mathrm{~s}$ & $\mathrm{~s}$ & $\mathrm{~s}$ & $\mathrm{~s}$ & $\mathrm{~s}$ & $\mathrm{~s}$ & 24 & 6284.5 & 3856.8 & 186.6 \\
\hline 3 & $\mathrm{t}$ & $\mathrm{t}$ & $\mathrm{t}$ & $t^{*} s$ & $\mathrm{t} * \mathrm{~s}$ & $t^{*} s$ & $\mathrm{t}^{*} \mathrm{~s}$ & $\mathrm{t} * \mathrm{~s}$ & $t^{*} s$ & 117 & 5866.6 & 3789.5 & 119.3 \\
\hline 4 & $\mathrm{t}$ & $=$ & $\mathrm{t}$ & $\mathrm{t}^{*} \mathrm{~s}$ & $\mathrm{t} * \mathrm{~s}$ & $\mathrm{t}^{*} \mathrm{~s}$ & $\mathrm{t}^{*} \mathrm{~s}$ & $\mathrm{t} * \mathrm{~s}$ & $\mathrm{t}^{*} \mathrm{~s}$ & 112 & 5869.5 & 3781.3 & 111.1 \\
\hline 5 & $\mathrm{k}$ & $=$ & $\mathrm{T}$ & $\mathrm{t}^{*} \mathrm{~s}$ & $\mathrm{t}^{*} \mathrm{~s}$ & $t^{*} s$ & $t^{*} s$ & $\mathrm{t} * \mathrm{~s}$ & $t^{*} s$ & 108 & 5874.2 & 3776.1 & 105.9 \\
\hline 6 & $\mathrm{k}$ & $=$ & $\mathrm{K}$ & $\mathrm{t}^{*} \mathrm{~s}$ & $\mathrm{t} * \mathrm{~s}$ & $t^{*} s$ & $t^{*} s$ & $\mathrm{t} * \mathrm{~s}$ & $t^{*} s$ & 104 & 5879.4 & 3771.2 & 101.1 \\
\hline 7 & $\mathrm{k}^{*} \mathrm{~s}$ & $=$ & $\mathrm{k}$ & $\mathrm{t}^{*} \mathrm{~s}$ & $\mathrm{t} * \mathrm{~s}$ & $\mathrm{t}^{*} \mathrm{~s}$ & $\mathrm{t}^{*} \mathrm{~s}$ & $\mathrm{t} * \mathrm{~s}$ & $\mathrm{t}^{*} \mathrm{~s}$ & 105 & 5869.1 & 3767.0 & 96.9 \\
\hline 8 & $\mathrm{k}^{*} \mathrm{~s}$ & $=$ & $\mathrm{k}$ & $\mathrm{t}$ & $\mathrm{t}$ & $\mathrm{t}$ & $\mathrm{t}^{*} \mathrm{~s}$ & $\mathrm{t} * \mathrm{~s}$ & $\mathrm{t}^{*} \mathrm{~s}$ & 88 & 5893.8 & 3748.0 & 77.8 \\
\hline 9 & $\mathrm{k}^{*} \mathrm{~s}$ & $=$ & $\mathrm{k}$ & $\mathrm{t}$ & $=$. & $\mathrm{t}$ & $t^{*} s$ & $\mathrm{t} * \mathrm{~s}$ & $t^{*} s$ & 82 & 5895.4 & 3737.0 & 66.8 \\
\hline 10 & $\mathrm{k}^{*} \mathrm{~s}$ & $=$ & $\mathrm{k}$ & $\mathrm{t}$ & $=$ & $\mathrm{k} / \mathrm{t}$ & $\mathrm{t}^{*} \mathrm{~s}$ & $\mathrm{t} * \mathrm{~s}$ & $t^{*} s$ & 83 & 5888.3 & 3734.7 & 64.5 \\
\hline 11 & $\mathrm{k}^{*} \mathrm{~s}$ & $=$ & $\mathrm{k}$ & $\mathrm{s}$ & $=$ & $\mathrm{s}$ & $\mathrm{t}^{*} \mathrm{~s}$ & $\mathrm{t} * \mathrm{~s}$ & $\mathrm{t}^{*} \mathrm{~s}$ & 75 & 5905.2 & 3728.9 & 58.7 \\
\hline 12 & $\mathrm{k}^{*} \mathrm{~s}$ & $=$ & $\mathrm{k}$ & $\mathrm{s}$ & $=$ & $\mathrm{s}$ & $t+s$ & $t+s$ & $t+s$ & 42 & 5957.1 & 3694.4 & 24.2 \\
\hline 13 & $\mathrm{k}^{*} \mathrm{~s}$ & $=$ & $\mathrm{k}$ & $\mathrm{s}$ & $=$ & $\mathrm{s}$ & $\mathrm{t}$ & $\mathrm{t}$ & $\mathrm{k}$ & 33 & 5971.9 & 3685.3 & 15.1 \\
\hline 14 & $\mathrm{k}^{*} \mathrm{~s}$ & $=$ & $\mathrm{k}$ & $\mathrm{s}$ & $=$ & $\mathrm{s}$ & $\mathrm{t}$ & $\mathrm{t}$ & $t+s$ & 42 & 5930.6 & 3678.3 & 8.1 \\
\hline 15 & $\mathrm{k} * \mathrm{~s}$ & $=$ & $\mathrm{k}$ & $\mathrm{s}$ & $=$ & $\mathrm{s}$ & $\mathrm{t}$ & $\mathrm{t}$ & $\mathrm{s}$ & 35 & 5940.3 & 3670.2 & 0 \\
\hline
\end{tabular}

Transitions are represented as $\psi^{i,-}$ from the departure stage $i$ to each of $\mathrm{S}, \mathrm{F}$, or $\mathrm{N}$. Variability sources were time (t), sex (s), and no variation over time or sex (k). Symbol * represents an interaction of term; + additive terms; = indicates the same parameter value as parameter on the immediate left column; and/indicates different variation between sexes. For example, $\mathrm{t} / \mathrm{k}$ is time variable for males and constant for females. $n p$ is number of parameters

the table are not presented for brevity. Model 1 is the starting sex-specific AS model, and model 2 is the most parsimonious model with time and sex invariant parameters, respectively. Models 3-7, 8-11, and 12-15 show structures that improved the estimates of recapture, survival, and breeding stage transitions, respectively. The best model (15; Table 3) had time invariant and equal recapture probabilities for birds in stages $S$ and $\mathrm{F}$ and a different and also time invariant recapture for birds in stage N. Survival, best modeled as time invariant and sex specific, was the same for successful and failed breeders, but different for non-breeders. The probabilities of interannual transition between breeding stages were best modelled as time dependent for birds starting as successful and failed breeders and time invariant but sex dependent for birds starting as nonbreeders.

The best model for breeding success suggested time variation (Fig. 2).

Estimates of probabilities of recapture, survival, transition between breeding stages and breeding success

Using the model with lowest $\Delta$ QAIC (model 15; Table 3), recapture probabilities were estimated as 0.991 (95\% CI: $0.980-0.996$ ) for successful and failed breeders and as 0.920 (95\% CI: 0.837-0.962) for non-breeders. Survival estimates for each sex and breeding stage are shown in Table 4 . Survival was high for successful and failed breeders, with

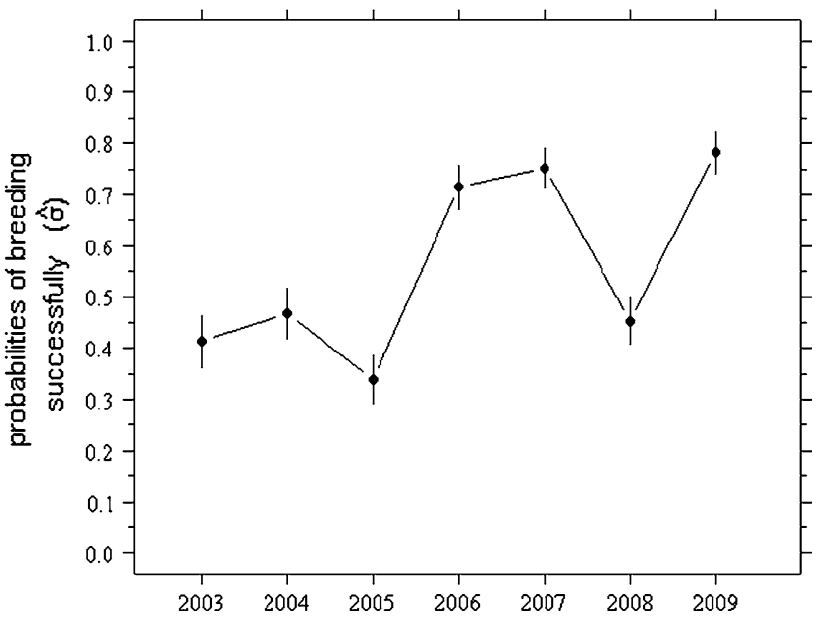

Fig. 2 Variation in breeding success of black-browed albatrosses at New Island over the study period. Vertical bars represent approximately $95 \%$ confidence limits predicted with a time-variant model

only marginal differences between sexes. The high survival and recapture of breeders indicated a high site fidelity to the breeding colonies. Non-breeding birds were less common, and among them, males had significantly higher survival probabilities than non-breeding females (Table 4). The mean survival across breeding stages was 0.951 (95\% CI: 0.934-0.963) for males and 0.933 (95\% CI: 0.914-0.948) for females, and across breeding stages and sexes, it was 0.942 (95\% CI: 0.930-0.952). 
Table 4 Mean estimates of probabilities of survival and transition between breeding stages (successful and failed breeders and non-breeders) and sexes in the black-browed albatross population at New Island, Falkland Islands. In parentheses are estimated $95 \%$ confidence intervals

\begin{tabular}{lll}
\hline Probability & Males & Females \\
\hline Adult survival & & \\
$\quad$ Successful breeders $\left(\phi^{S}\right)$ & $0.954(0.936-0.967)$ & $0.940(0.921-0.955)$ \\
Failed breeders $\left(\phi^{F}\right)$ & $0.954(0.936-0.967)$ & $0.940(0.921-0.955)$ \\
Non-breeders $\left(\phi^{N}\right)$ & $0.914(0.820-0.961)$ & $0.811(0.667-0.901)$ \\
Transition of breeding stages & & \\
Successful to successful $\left(\psi^{S, S}\right)$ & $0.592(0.557-0.625)$ & $0.592(0.557-0.625)$ \\
Successful to failed $\left(\psi^{S, F}\right)$ & $0.350(0.318-0.383)$ & $0.350(0.318-0.383)$ \\
Successful to non-breeder $\left(\psi^{S, N}\right)$ & $0.058(0.044-0.077)$ & $0.058(0.044-0.077)$ \\
Failed to successful $\left(\psi^{S, F}\right)$ & $0.513(0.477-0.550)$ & $0.513(0.477-0.550)$ \\
Failed to failed $\left(\psi^{F, F}\right)$ & $0.374(0.339-0.410)$ & $0.374(0.339-0.410)$ \\
Failed to non-breeder $\left(\psi^{F, N}\right)$ & $0.113(0.092-0.139)$ & $0.113(0.092-0.139)$ \\
Non-breeder to successful $\left(\psi^{N, S}\right)$ & $0.307(0.212-0.422)$ & $0.490(0.333-0.650)$ \\
Non-breeder to failed $\left(\psi^{N, F}\right)$ & $0.207(0.129-0.316)$ & $0.423(0.274-0.587)$ \\
Non-breeder to non-breeder $\left(\psi^{N, N}\right)$ & $0.486(0.373-0.600)$ & $0.087(0.028-0.236)$ \\
\hline
\end{tabular}

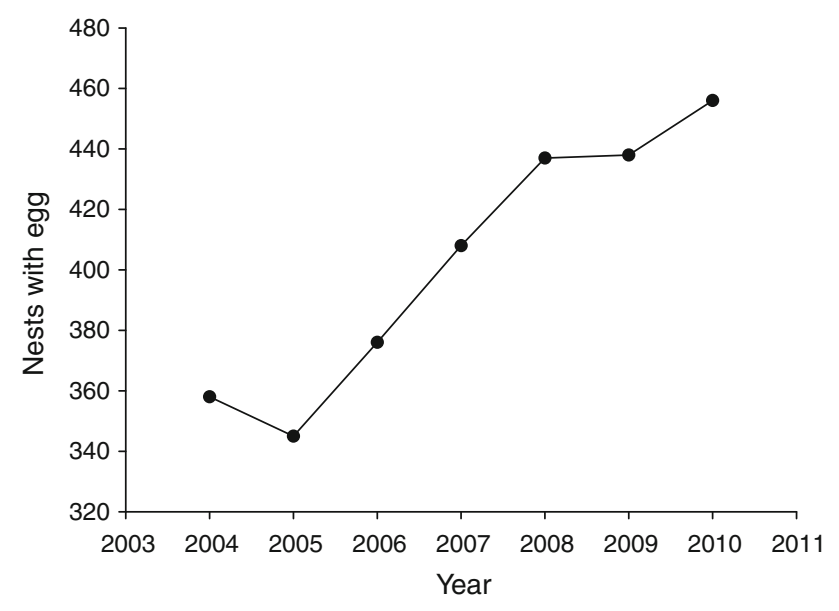

Fig. 3 Trends in the number of active nests (nests where an egg was laid) in 6 intensively monitored black-browed albatross sub-colonies at the Settlement Rookery, New Island, Falkland Islands

Transitions between breeding stages indicated that successful birds of both sexes had a higher tendency to breed again and remain successful than breed again and fail or defer breeding, in this order. Failed breeders of both sexes tended more to succeed than to fail at the next breeding attempt, but deferred breeding more than successful breeders. Non-breeders of both sexes tended to breed again in subsequent occasions, although the probability to breed again was much higher for females than males. In agreement, non-breeding males stayed as non-breeders significantly more than females (Table 4).

The mean breeding success over the study period was 0.564 chicks per egg laid (95\% CI: 0.199-0.933), and its interannual variation is shown in Fig. 2.

The number of nesting pairs in the intensively monitored nesting colonies showed a clear positive trend over the study period (Fig. 3). The growth rate, calculated from the
Jolly-Seber model for recruitment and population growth, was $\lambda=1.040$ (95\% CI: $1.021-1.058)$.

The 2003/04 mortality event

An unusual mortality event took place during the 2003/04 breeding season. In an area of the Settlement Rookery with approximately 1,200 albatross nests, 15 adult birds (including 4 study birds) were found dead in November and December. In the 7 subsequent breeding seasons, not a single study bird was found dead at the colony.

Deaths were apparently sudden. All 4 study birds that died were found 2-12 m from their nests. On December 20, 2003, we found an adult albatross sitting on the ground, with half-stretched wings, in the middle of a colony. The bird could crawl and keep its head up, but could not stand on its feet, and died $1 \mathrm{~h}$ later. This bird, and 3 others that were summarily autopsied, had good layers of fat under the skin. They also had the intestine covered by a network of blood vessels that appeared enlarged and sharply outlined, a sign of inflammation consistent with paralytic shellfish poisoning-PSP (Shumway et al. 2003). All 4 birds had full or partly full stomachs with relatively fresh lobster krill Munida sp. and well-digested fish. Body masses of 3 freshly dead and intact birds were $4.05,3.45$, and $3.00 \mathrm{~kg}$, well within the normal range for incubating black-browed albatrosses on New Island (own unpubl. data).

\section{Discussion}

This paper reports the first demographic analysis of the black-browed albatross at New Island using robust CMR methods. The analysis deliberately selected state-of-the-art multistate CMR models and a life cycle that reflected the 
interannual transitions of birds across breeding stages (Nevoux et al. 2010). This has the advantage to provide more robust and comparable estimates of survival. However, the current time series for New Island is still short to offer a good basis for comparison of interannual breeding transitions, especially in relation to sources of temporal variation. In this regard, the analysis should be repeated once the time series is augmented.

The survival probabilities estimated by the present study (mean 0.942) are well within the range of those found for other black-browed albatross populations: 0.957 (pre-1998) and 0.901 (post-1988) at Bird Island, South Georgia (Arnold et al. 2006), where the population is in rapid decline (Poncet et al. 2006); 0.915 at Macquarie Island, for a population presumed to be stable (Terauds et al. 2005); 0.917 for the mostly stable population sampled on Kerguelen (Rolland et al. 2008). The closely related Campbell albatross T. (melanophris) impavida on Campbell Island showed a survival probability of 0.945 during a period of slow population increase (Waugh et al. 1999). Breeding success of black-browed albatrosses is highly variable between years and populations (Nevoux et al. 2010), but the values obtained on New Island (0.564) seem not to be low for Thalassarche albatrosses (see review in Cuthbert et al. 2003). Other known parameters are equally favourable. The incidence of breeding deferral reported here is low for annual breeding Thalassarche albatrosses (Cuthbert et al. 2003). Although we have no information on immature survival or on the mean age of first breeding, the first known-age recruits to the nesting colonies were 6 years old in October 2009, which equals the youngest records for first breeding known from other populations (reviewed in Prince et al. 1994).

In the absence of data on immature survival, it is not as yet possible to model the New Island population trajectory, but we should point out that the adult survival rates (which are the main drivers of albatross population trajectories) on New Island are higher than those of several black-browed albatross populations known to be stable or increasing, as reviewed above. Nevertheless, the South Georgia population has known a decline in a period with very high adultsurvival rates (0.957), although this seemed to be driven by a combination of unusually low nesting success and low nesting probabilities, yielding a breeding output of only 0.168 fledglings per adult female per year (Arnold et al. 2006). Therefore, the observed population increase at our study colonies of New Island seems to be broadly consistent with the demographic parameters already determined.

It may be pointed out that as the New Island colony is a small percentage of the total Falkland Islands population, it is not representative of overall demographic trends. This may indeed be the case, particularly with regard to parameters that can be influenced by localised factors, such as chick predation levels and intra-specific competition, which may impact on nesting success. Differential recruitment to different colonies, for example, could also result in our study plots showing an expansion in nest numbers, while the general Falklands population declined. Indeed, it has been shown in several seabird species that small colonies tend to show higher population growth rates than large ones (e.g., Lewis et al. 2001). However, these local effects are less likely to apply to adult survival rates. New Island albatrosses are known to range widely over the Patagonian shelf and overlap extensively at sea with birds from other Falkland colonies during incubation and the non-breeding season (Grémillet et al. 2000; Huin 2002; BirdLife International 2004), although the same may not be true during chick rearing (own unpubl. data). Hence, New Island individuals may be mostly subject to the same factors influencing adult mortality of birds nesting at other Falkland colonies.

Can the estimated adult-survival probabilities be reconciled with the available information on albatross bycatch in the Southwest Atlantic? This is difficult to assess, given that (i) known mortality rates reported from trawl fisheries are likely to be seriously underestimated (Watkins et al. 2008), (ii) there are no bycatch statistics for several relevant legal fisheries nor for the IUU (illegal unreported and unregulated) fishing fleet, and (iii) there are rumours of some intentional catch of seabirds for food by the squid fishing fleet. The annual breeding black-browed albatross population of the Falkland Islands is ca 400,000 pairs (Huin and Reid 2007). Including 7\% experienced individuals that skip breeding each year, plus all the adult-plumaged pre-breeders (mostly aged 4-10 years), this population will easily exceed 1 million adult-plumaged individuals. The combined estimates for (adult-plumaged) albatross mortality along the Patagonian shelf and shelf break maybe of the order of ca. 5,000 individuals per year (from Neves and Olmos 1997; Yorio and Caille 1999; Olmos et al. 2000; Favero et al. 2003; Reid et al. 2004; Reid and Edwards 2005; Crofts 2006; Gandini and Frere 2006; GonzálezZevallos and Yorio 2006; Laich et al. 2006; Moreno et al. 2006; Sullivan et al. 2006b; González-Zevallos et al. 2007; Otley et al. 2007; Bugoni et al. 2008; Moreno et al 2008; Sancho 2009; Jiménez et al. 2009, 2010; Favero et al. 2010). Even if we assume that the true mortality is twice as high as the above estimate (which is not unreasonable) and is entirely of birds from the local population, fisheries-related mortality would affect less than $1 \%$ of the birds from the Falklands. These calculations, although preliminary and with a high degree of uncertainty, suggest a level of known bycatch that is potentially compatible with the survival probabilities recorded in our study population.

Could the differential mortality rates of New Island males and females reflect a difference in susceptibility to 
fisheries-related mortality? The present analysis cannot exclude such possibility, but a recent review on the subject did not suggest adult females to be more susceptible to bycatch in fisheries (Bugoni et al. 2010). In fact, the lower survival of New Island females is mostly related to the nonbreeder section of the population (Table 4). Given that females show a lesser attachment to nest sites and that we have found birds shifting sub-colonies, the possibility of occasional emigration to nearby nesting sites in cliffs (giving the impression of higher mortality) cannot be excluded, particularly considering that non-breeding females may be more likely to search for new nesting mates and sites.

The discussion above should not be taken as evidence that current bycatch levels in Patagonian Shelf fisheries are acceptable and that no further mitigation measures are necessary. First, there are still important fisheries-related mortality sources that need to be quantified. Second, even low mortality levels might tip the balance and lead to population declines, should environmental conditions become less favourable to black-browed albatrosses. Third, it is not only black-browed albatrosses that are potentially impacted by bycatch in the region. Threatened seabirds such as large albatrosses Diomedea spp. and petrels Procellaria spp. are also known to be affected (e.g., Bugoni et al. 2008; Jiménez et al. 2009; Favero et al. 2010).

A "red tide" affected most seabird life in the West Falklands in December 2002 and January 2003 (Uhart et al. 2004). In the order of tens of thousands of penguins, albatrosses, and other seabirds were estimated to have died from paralytic shellfish poisoning (PSP) in this event (Uhart et al. 2004). Our data strongly suggest that there was a (much smaller) sequel to this event in late 2003, as New Island albatrosses showed an abnormal mortality incidence at the colony and symptoms consistent with PSP (see Shumway et al. 2003). The event did not have a measurable impact on survival probabilities at the population level, but a larger event, such as the 2002/03 one, may have been different. Unfortunately, the present demographic study started too late to evaluate this. Still, the potential of harmful algal blooms to impact albatrosses should not be overlooked, particularly considering that such events may be becoming more frequent in many regions of the world (Shumway et al. 2003).

The high survival rates documented here may partly reflect recent efforts to mitigate fisheries-related mortality that were and are still being made by Falkland Islands and other states/fisheries in the region (Reid and Edwards 2005; Sullivan et al. 2006a; González-Zevallos et al. 2007; Otley et al. 2007; Moreno et al. 2008; Favero et al. 2010; http:// www.rspb.org.uk/supporting/campaigns/albatross/). There are not enough data on pre- and post-mitigation survival rates to adequately evaluate such hypothesis. Further mitigation initiatives should be encouraged, as they may be critical to help other species and to buffer the black-browed albatross population against predicted global changes in marine ecosystems (Barange et al. 2010).

Finally, we believe that more demographic data, from a wider range of sites, coupled with studies of albatross at-sea distribution and overlap with fisheries are urgently needed to obtain a more complete image of the demography, threats, and conservation status of the black-browed albatross in the Falkland Islands and the Patagonian shelf.

Acknowledgments The long-term monitoring of black-browed albatrosses on New Island has benefited from the committed longterm support of the Falkland Islands Government, as well as from projects funds provided by Fundação para a Ciência e Tecnologia (FCT-Portugal) through Projecto Albatroz (PTDC/MAR/099366/ 2008) and as part of the Programa Plurianual (UI\&D 331/94). Further support was received from the Foreign and Commonwealth Office through an Overseas Territories Environment Programme (OTEP) grant (FAL 201). The New Island Conservation Trust, an NGO and charity, supported field studies on their New Island reserve, through the supply of research facilities, accommodation, and subsistence. Without the support and encouragement from Ian Strange, this study would never have taken place. Rafael Matias, Miguel Lecoq, and Orea Anderson helped with fieldwork. Maria Strange, Shona Strange, Georgina Strange, Dan Birch, Helen Otley, Nick Rendell, Anton Wolfaardt and Leigh Wolfaardt provided logistical and moral support in the field and in Stanley. Inês Catry, John Croxall, Christophe Barbraud and two anonymous reviewers commented on a previous draft. All work was approved by the Falkland Islands Government.

\section{References}

ACAP (2009) ACAP Species Assessment: black-browed albatross Thalassarche melanophris. http://www.acap.aq. Accessed on 1 September 2009

Arnold JM, Brault S, Croxall JP (2006) Albatross populations in peril: a population trajectory for black-browed albatrosses at South Georgia. Ecol Appl 16:419-432

Barange M, Field JG, Harris RP, Hofmann EE, Perry RI, Werner FE (eds) (2010) Marine ecosystems and global change. Oxford University Press, Oxford

BirdLife International (2004) Tracking ocean wanderers. The global distribution of albatrosses and petrels. Results from the global procellariiform tracking workshop, 1-5 September 2003, Gordon's Bay, South Africa. BirdLife International, Cambridge

Bugoni L, Mancini PL, Monteiro DS, Nascimento L, Neves T (2008) Seabird bycatch in the Brazilian pelagic longline fishery and a review of capture rates in the Southwestern Atlantic Ocean. Endang Species Res 5:137-147

Bugoni L, Griffiths K, Furness RW (2010) Sex-biased incidental mortality of albatrosses and petrels in longline fisheries: differential distributions at sea or differential access to baits mediated by sexual size dimorphism? J Orn. doi:10.1007/ s10336-010-0577-x

Burnham KP, Anderson DR (1998) Model selection and inference: a practical information-theoretic approach. Springer, New York

Choquet R, Reboulet AM, Pradel R, Gimenez O, Lebreton J-D (2004) M-SURGE: new software specifically designed for multistate capture-recapture models. Anim Biodivers Conserv 27:207-215

Choquet R, Lebreton J-D, Gimenez O, Reboulet AM, Pradel R (2009) U-CARE: utilities for performing goodness of fit tests and manipulating Capture-Recapture data. Ecography 32:1071-1074 
Crofts S (2006) Seabird interactions in the Falkland Islands Loligo trawl fishery, 2005/2006. Falklands Conservation, Stanley

Cuthbert R, Ryan PG, Cooper J, Hilton G (2003) Demography and population trends in the Atlantic yellow-nosed albatross. Condor 105:439-452

Favero M, Khatchikian E, Arias A, Rodriguez MPS, Cañete G, Mariano-Jelicich R (2003) Estimates of seabird by-catch along the Patagonian Shelf by Argentine longline fishing vessels, 1999-2001. Bird Conserv Int 13:273-281

Favero M, Blanco G, García G, Copello S, Seco Pon JP, Frere E, Quintana F, Yorio P, Rabuffetti F, Cañete G, Gandini P (2010) Seabird mortality associated with ice trawlers in the Patagonian shelf: effect of discards on the occurrence of interactions with fishing gear. Anim Conserv. doi:10.1111/j.1469-1795.2010. 00405.x

Gandini P, Frere E (2006) Spatial and temporal patterns in the bycatch of seabirds in the Argentinean longline fishery. Fish Bull 104:482-485

González-Zevallos D, Yorio P (2006) Seabird use of discards and incidental captures at the Argentine hake trawl fishery in the Golfo San Jorge, Argentina. Mar Ecol Prog Ser 316:175-183

González-Zevallos D, Yorio P, Caille G (2007) Seabird mortality at trawler warp cables and a proposed mitigation measure: a case study in Golfo San Jorge, Patagonia, Argentina. Biol Conserv 136:108-116

Grémillet D, Wilson RP, Wanless S, Chater T (2000) Black-browed albatrosses, international fisheries and the Patagonian Shelf. Mar Ecol Prog Ser 195:269-280

Huin N (2002) Foraging distribution of the black-browed albatross Thalassarche melanophris breeding in the Falkland Islands. Aquat Conserv: Mar Freshw Ecosyst 12:89-99

Huin N, Reid T (2007) Census of the black-browed albatross population of the Falkland Islands. Falkland Conservation, Stanley

IUCN (2008) IUCN red list of threatened species. http://www. iucnredlist.org. Accessed 1 September 2009

Jiménez S, Domingo A, Brazeiro A (2009) Seabird bycatch in the southwest Atlantic: interaction with the Uruguayan pelagic longline fishery. Polar Biol 32:187-196

Jiménez S, Abreu M, Pons M, Ortiz M, Domingo A (2010) Assessing the impact of the pelagic longline fishery on albatrosses and petrels in the Southwest Atlantic. Aquat Living Resour 23:49-64

Laich AG, Favero M, Mariano Jelicich R, Blaco G, Cañete G, Arias A, Rodriguez PS, Brachetta H (2006) Environmental and operational variability affecting the mortality of black-browed albatrosses associated with long-liners in Argentina. Emu 106:21-28

Lebreton J-D, Pradel R (2002) Multistate recapture models: modelling incomplete individual histories. J Appl Stat 29:353-369

Lewis S, Sherrat TN, Hamer KC, Wanless S (2001) Evidence of intraspecific competition for food in a pelagic seabird. Nature 412:816-819

Moreno CA, Arata JA, Rubilar P, Hucke-Gaete R, Robertson G (2006) Artisanal longline fisheries in Southern Chile: lessons to be learned to avoid incidental seabird mortality. Biol Conserv 127:27-36

Moreno CA, Castro R, Mújica LJ, Reyes P (2008) Significant conservation benefits obtained from the use of a new fishing gear in the Chilean Patagonian toothfish fishery. CCAMLR Sci 15:79-91

Neves T, Olmos F (1997) Albatross mortality in fisheries off the coast of Brazil. In: Robertson G, Gales R (eds) Albatross biology and conservation. Surrey Beally \& Sons, Chipping Norton, pp 214-219

Nevoux M, Forcada J, Barbraud C, Croxall J, Weimerskirch H (2010) Bet-hedging response to environmental variability, an intraspecific comparison. Ecology 91:2416-2427
Olmos F, Bastos GC, Neves TS (2000) Estimating seabird by-catch in Brazil. Second international conference on the biology and conservation of albatrosses and other petrels. 8-12 May, Waikiki, Hawaii

Otley HM, Reid TA, Pompert J (2007) Trends in seabird and Patagonian toothfish Dissostichus eleginoides longliner interactions in Falkland Islands waters, 2002/03 and 2003/04. Mar Ornithol 35:47-55

Poncet S, Robertson G, Phillips RA, Lawton K, Phalan B, Trathan PN, Croxall JP (2006) Status and distribution of wandering, black-browed and grey-headed albatrosses breeding at South Georgia. Polar Biol 29:772-781

Pradel R (1996) Utilization of capture-mark-recapture for the study of recruitment and population growth rate. Biometrics 52:703-709

Pradel R, Winterbert CMA, Gimenez O (2003) A proposal for a goodness-of-fit test to the Arnason-Schwarz multisite capturerecapture model. Biometrics 59:43-53

Prince PA, Rothery P, Croxall JP, Wood AG (1994) Population dynamics of black-browed and grey headed albatrosses Diomedea melanophris and D. chrysostoma at Bird Island, South Georgia. Ibis 136:50-71

R Development Core Team (2009) R: a language and environment for statistical computing. $\mathrm{R}$ foundation for statistical computing, Vienna, Austria. ISBN 3-900051-07-0, URL http://www. R-project.org

Reid T, Edwards M (2005) Consequences of the introduction of Tori lines in relation to seabird mortality in the Falkland Islands trawl fishery, 2004/2005. Falklands Conservation, Stanley

Reid TA, Sullivan BJ, Pompert J, Enticott JW, Black AD (2004) Seabird mortality associated with Patagonian Toothfish (Dissostichus eleginoides) longliners in Falkland Islands waters. Emu 104:317-325

Rolland V, Barbraud C, Weimerskirch H (2008) Combined effects of fisheries and climate on a migratory long-lived seabird. J Appl Ecol 45:4-13

Sancho E (2009) Seabird mortality associated with trawlers in the Falkland Islands waters during 2007 and 2008. Falklands Conservation, Stanley

Shumway SE, Allen SM, Boersma PD (2003) Marine birds and harmful algal blooms: sporadic victims or under-reported events? Harmful Algae 2:1-17

Strange IJ (2008) Aerial surveys of black-browed albatross Thalassarche melanophris breeding colonies in the Falkland Islands: the methodology employed and comparisons with surveys carried out in 1986, 2005, 2006 and 2007. Design in Nature \& Falkland Islands Wildlife, Stanley

Sullivan BJ, Brickle P, Reid TA, Bone DG, Middleton DAJ (2006a) Mitigation of seabird mortality on factory trawlers: trials of three devices to reduce warp cable strikes. Polar Biol 29:745-753

Sullivan BJ, Reid TA, Bugoni L (2006b) Seabird mortality on factory trawlers in the Falkland Islands and beyond. Biol Conserv 131:495-504

Terauds A, Gales R, Alderman R (2005) Trends in numbers and survival of black-browed (Talassarche melanophrys) and greyheaded ( $T$. chrysostoma) albatrosses breeding on Macquarie Island. Emu 105:159-167

Uhart M, Karesh W, Cook R, Huin N, Lawrence K, Guzman L, Pacheco H, Pizarro G, Mattsson R, Mörner T (2004) Paralytic shellfish poisoning in gentoo penguins (Pygoscelis papua) from the Falkland (Malvinas) Islands. In: Proceedings of the 2004 AAZV, AAWV and WDA joint conference, USA, pp 481-486

Watkins BP, Petersen SL, Ryan PG (2008) Interactions between seabirds and deep-water hake trawl gear: an assessment of impacts in South African waters. Anim Conserv 11:247-254

Waugh SM, Weimerskirch H, Moore PJ, Sagar PM (1999) Population dynamics of black-browed and grey headed albatrosses 
Diomedea melanophrys and D. chrysostoma at Campbell Island, New Zealand, 1942-1996. Ibis 141:216-225

White GC, Burnham KP (1999) Program MARK: survival estimation from populations of marked animals. Bird Study 46:120-138
Yorio P, Caille G (1999) Seabird interactions with coastal fisheries in Northern Patagonia: use of discards and incidental captures in nets. Waterbirds 22:207-216 